\title{
Adherence to dietary guidelines and 15-year risk of all-cause mortality
}

\author{
Joanna Russell $^{1}$, Victoria Flood ${ }^{1 *}$, Elena Rochtchina ${ }^{2}$, Bamini Gopinath ${ }^{2}$, Margaret Allman-Farinelli ${ }^{3}$, \\ Adrian Bauman ${ }^{4}$ and Paul Mitchell ${ }^{2}$ \\ ${ }^{1}$ School of Health Sciences, Faculty of Health and Behavioural Sciences, University of Wollongong, Wollongong, NSW 2522, \\ Australia \\ ${ }^{2}$ Centre for Vision Research (Westmead Millennium Institute), University of Sydney, NSW 2006, Australia \\ ${ }^{3}$ School of Molecular Bioscience, University of Sydney, NSW 2006, Australia \\ ${ }^{4}$ School of Public Health, University of Sydney, NSW 2006, Australia
}

(Submitted 25 May 2011 - Final revision received 8 March 2012 - Accepted 17 March 2012 - First published online 9 May 2012)

\section{Abstract}

Past investigation of diet in relation to disease or mortality has tended to focus on individual nutrients. However, there has been a recent shift to now focus on overall patterns of food intake. The present study aims to investigate the relationship between diet quality reflecting adherence to dietary guidelines and mortality in a sample of older Australians, and to report on the relationship between core food groups and diet quality. This was a population-based cohort study of persons aged 49 years or older at baseline, living in two postcode areas west of Sydney, Australia. Baseline dietary data were collected during 1992-4, from 2897 people using a 145-item Willett-derived FFQ. A modified version of the Healthy Eating Index for Australians was developed to determine diet quality scores. The Australian National Death Index provided 15-year mortality data using multiple data linkage steps. Hazard risk (HR) ratios and $95 \%$ CI for mortality were assessed for diet quality. Subjects in quintile 5 (highest) of the Total Diet Score had a $21 \%$ reduced risk of all-cause mortality (HR $0.79,95 \%$ CI $\left.0.63,0.98, P_{\text {trend }}=0.04\right)$ compared with those in quintile 1 (lowest) after multivariate adjustment. The present study provides longitudinal support for a reduced risk of all-cause mortality in an older population who have greater compliance with published dietary guidelines.

\section{Key words: Total Diet Score: Mortality: Older adults}

In the past, research has focused on examining the relationship of individual nutrients to total and cause-specific mortality. There is a need, however, to examine total diet, as nutrients are not consumed independently but together within a variety of foods in the diet. In recent years, research into the relationship between overall diet quality and the risk of mortality or of developing chronic disease has expanded $^{(1-6)}$. There have been two frequent approaches used to measure diet quality, one that uses statistical methods such as cluster analysis, factor analysis or principal component analysis to derive dietary patterns from collected data giving an indication of eating behaviours ${ }^{(5,7-10)}$. The alternative approach group foods 'a priori' that are representative of current nutrition knowledge in the form of dietary guidelines or other dietary recommendations ${ }^{(11,12)}$. This may be a more useful tool in public health practice to assess a population's adherence to current dietary guidelines based on empirical evidence.
Based on the latter approach, a number of diet quality indices have already been developed based on dietary guidelines including the Diet Quality Index ${ }^{(13)}$, Healthy Eating Index ${ }^{(14)}$ and Dietary Guidelines Index ${ }^{(15)}$. In Australia, one study has shown overall improvement in diet quality over time and cross-sectional findings have reported that higher diet quality scores were inversely associated with prevalent diabetes in men and pre-diabetes in women ${ }^{(16)}$. However, no studies have assessed the effect of diet quality, in terms of adhering to dietary guidelines, on mortality or morbidity over time. Nor have any known studies addressed diet quality in an older adult population.

To investigate the longitudinal effect of dietary guideline adherence and all-cause mortality in a cohort of older Australians, we developed a tool modelled on both Australian and US diet quality indices ${ }^{(17,18)}$. The objectives of the present study were, first, to investigate diet quality, defined as adherence to the Dietary Guidelines for Australian Adults (DGAA) at

Abbreviations: AGHE, Australian Guide to Healthy Eating; BMES, Blue Mountains Eye Study; DGAA, Dietary Guidelines for Australian Adults; HR, hazard risk; MET.min, metabolic equivalents.min; TDS, Total Diet Score.

*Corresponding author: Dr V. Flood, fax +6124221 3486, email vflood@uow.edu.au 
baseline and report its relationship to core food groups among older adults living in the Blue Mountains region of Australia. The second objective was to identify the relationship between diet quality and mortality risk after 15 years followup of this cohort.

\section{Methods \\ Study used}

The data used for this analysis were collected as part of the Blue Mountains Eye Study (BMES). Full details of the study design have been reported previously ${ }^{(19,20)}$. Briefly, the BMES is a population-based cohort study of vision and common eye diseases in residents aged 49 years or older living in a two-postcode region, west of Sydney, Australia. Baseline data were collected from 1992 to 1994 (BMES1) with follow-up conducted at 5-year intervals (1997-9, 20024 and 2007-9). BMES1 baseline examinations included 3654 subjects aged 49-97 years. Mortality data were obtained from the Australian National Death Index by matching with BMES1 subjects up until December 2007. The study followed the recommendations of the Declaration of Helsinki and was approved by the University of Sydney and Sydney West Area Health Service Human Research Ethics Committees. All subjects provided written informed consent.

\section{Dietary assessment}

The semi-quantitative FFQ included 145 items and was adapted for the Australian diet from a Willett $\mathrm{FFQ}^{(19)}$. Subjects used a nine-category frequency scale, ranging from never to four times per $\mathrm{d}$, to indicate usual consumption of particular food items during the past year. The FFQ was attempted and returned by 3267 participants ( $82.4 \%$ response); of these FFQ, 2897 were available for analysis (79.3\% of subjects examined). Participants were excluded if their FFQ had more than twelve FFQ items missing, had energy intakes $<2500 \mathrm{~kJ}$ or $>18000 \mathrm{~kJ}$, or had implausible records in the upper or lower $2 \%$ of the distribution after the nutrient data had been re-examined.

The FFQ was validated by comparing nutrients from the FFQ with three $4 \mathrm{~d}$ weighed food records collected over 1 year ( $n$ 79). Most nutrient correlations were between 0.50 and 0.60 for energy-adjusted intakes, similar to other validated FFQ studies ${ }^{(19,21)}$. The Australian Tables of Food Composition were used to estimate nutrient intakes, and data were entered and analysed using NUTTAB90 and a purpose-built software analysis system $^{(21)}$.

\section{Total Diet Score development}

A modified version of the Australian diet quality index ${ }^{(17)}$, based on the DGAA ${ }^{(22)}$ and the Australian Guide to Healthy Eating (AGHE) ${ }^{(23)}$, was used to establish the Total Diet Score (TDS), assessing adherence to the Australian dietary guidelines. Our version closely follows the US 2005 Dietary Guidelines Adherence Index which takes account of changes to the 2005 American Dietary Guidelines that has a focus on overconsumption and energy density ${ }^{(18)}$, issues also applicable to the Australian population. TDS were allocated for intake of selected food groups and nutrients for each participant as described in the DGAA (for details on FFQ food groupings, see Supplementary material 1, available online). The TDS is divided into ten components, and each component has a possible score ranging from 0 to 2 (Fig. 1). A maximum score of 2 was given to subjects who met the recommendations with prorated scores for lower intakes. These were then summed, providing a final score ranging between 0 and 20, with higher scores indicating closer adherence to the dietary guidelines.

The TDS account for both food intake and optimal choice, with scores allocated to reflect intake characteristics from both sources. Food intake scores were based on total intakes of vegetables, fruit, cereals and breads, meat, fish, poultry and/or alternatives and dairy as well as $\mathrm{Na}$, alcohol, sugar and extra food intakes. Optimal choice scores determined intakes of foods with greater dietary benefits including serves of whole-grain cereals, lean red meat, low- or reduced-fat milk $v$. whole milk, low saturated fat intake and fish consumption. Cut points for scores were determined from the recommended number of serves given in the AGHE with some exceptions ${ }^{(23)}$. We replaced the AGHE's recommended two serves per $d$ of fruit with three serves per $\mathrm{d}$ and the number of vegetables consumed per $\mathrm{d}$ from five serves to seven serves to allow for self-reported FFQ overestimation as determined by the validity study ${ }^{(19)}$. The alcohol cut points reflect the guidelines about alcohol consumption in Australia (DGAA), in which it is recommended, when alcohol is consumed, that men consume a maximum of two standard drinks per $\mathrm{d}$ and women one standard drink per $\mathrm{d}^{(22)}$. Moderate intakes of sugar were determined from the DGAA where they found no evidence that consuming a diet up to $15-20 \%$ of energy from sugar was detrimental to a healthy diet ${ }^{(22)}$. Extra foods were defined as foods that were energy dense containing higher levels of sugar, fat or salt with one serve equivalent to $600 \mathrm{~kJ}^{(23)}$. Examples described in the AGHE include biscuits, cakes, soft drinks, ice cream, pies, hot chips and high-fat takeaway items. Identification and characterisation of additional extra foods were determined from research by Rangan et al. ${ }^{(24)}$.

To follow dietary guideline recommendations as closely as possible, the non-dietary component of the AGHE, preventing weight gain, was included in the TDS. In this way, half the score was assigned to energy balance, calculated as the ratio of energy intake:energy expenditure with a maximum score given for ratios falling between 0.76 and 1.24 , defined as the $95 \%$ confidence levels of agreement between energy intake and energy expenditure ${ }^{(25)}$. The other half of the score was assigned to leisure-time physical activity. Physical activity levels were self-reported using questions from the Australian National Heart Foundation's Risk Factor Prevalence Surveys ${ }^{(26)}$. Details of walking exercise and the performance of moderate or vigorous activities were used to calculate metabolic equivalents.min (MET.min) as described by Brown \& Bauman ${ }^{(27)}$. Subjects were categorised 
into low (0 to $<600$ MET.min), moderate ( $\geq 600$ to $<1500$ MET.min) and high ( $\geq 1500$ MET.min) tertiles of physical activity. The physical activity guidelines suggest $30 \mathrm{~min}$ of moderate activity, preferably on all days of the week and 600 MET.min is comparable to $30 \mathrm{~min}$ of physical activity on $5 \mathrm{~d}$ of a week ${ }^{(27)}$. Subjects in the highest MET tertile scored 1 point, reducing to a 0 point score for subjects in the lowest MET tertile.
Drinking adequate water and food safety categories from the DGAA were not included in the analysis because data on these items were not available in the present study.

\section{Analysis variables}

Demographic and lifestyle covariates used in this analysis were taken from an interviewer-administered questionnaire completed at the baseline visit. BMI was calculated as

\begin{tabular}{|c|c|c|c|c|}
\hline $\begin{array}{c}\text { Dietary guideline/ } \\
\text { component }\end{array}$ & Score & Component subscore & & Total score \\
\hline $\begin{array}{l}\text { 1. Eat plenty of } \\
\text { vegetables, } \\
\text { legumes and } \\
\text { fruit }\end{array}$ & $\begin{array}{l}\text { Total vegetable } \\
\text { serves/d* } \\
\text { Vegetable variety } \\
\text { score/d } \\
\text { Total fruit serves/d } t\end{array}$ & $\begin{array}{l}7 \text { serves } \\
5 \cdot 6 \text { serves } \\
4 \cdot 2 \text { serves } \\
2 \cdot 8 \text { serves } \\
1 \cdot 4 \text { serves } \\
\geq 1 \text { serve green } \\
\geq 1 \text { serve orange } \\
\geq 1 \text { serve of cruciferous } \\
\geq 1 \text { serve of tuber or bulb } \\
\geq 0 \cdot 5 \text { serves of legumes } \\
3 \text { serves } \\
2 \text { serves }\end{array}$ & $\begin{array}{l}0 \cdot 5 \\
0 \cdot 4 \\
0 \cdot 3 \\
0 \cdot 2 \\
0 \cdot 1 \\
0 \cdot 1 \\
0 \cdot 1 \\
0 \cdot 1 \\
0 \cdot 1 \\
0 \cdot 1 \\
1 \\
0.5\end{array}$ & 2 \\
\hline $\begin{array}{l}\text { 2. Eat plenty of } \\
\text { cereals, } \\
\text { preferably } \\
\text { whole grain/ } \\
\text { meal }\end{array}$ & $\begin{array}{l}\text { Total cereals serves/d } \\
\text { Women } \\
\text { Men } \\
\text { Whole-grain cereal } \\
\text { serves/d } \\
\text { Women } \\
\text { Men }\end{array}$ & $\begin{array}{l}4 \text { serves } \\
3 \text { serves } \\
2 \text { serves } \\
1 \text { serve } \\
6 \text { serves } \\
5 \text { serves } \\
4 \text { serves } \\
3 \text { serves } \\
2 \text { serves } \\
1 \text { serve } \\
\\
4 \text { serves } \\
3 \text { serves } \\
2 \text { serves } \\
1 \text { serve } \\
6 \text { serves } \\
5 \text { serves } \\
4 \text { serves } \\
3 \text { serves } \\
2 \text { serves } \\
1 \text { serve }\end{array}$ & $\begin{array}{l}1 \\
0.75 \\
0.5 \\
0.25 \\
1 \\
0.83 \\
0.66 \\
0.5 \\
0.33 \\
0.166 \\
\\
1 \\
0.75 \\
0.5 \\
0.25 \\
1 \\
0.83 \\
0.66 \\
0.5 \\
0.33 \\
0.166\end{array}$ & 2 \\
\hline $\begin{array}{l}\text { 3. Include lean } \\
\text { meats, fish, } \\
\text { poultry and/ } \\
\text { or alternatives }\end{array}$ & $\begin{array}{l}\text { Meat/alternative/d } \\
\text { Lean red meat/week } \\
\text { (i.e. }>0.428 / d \text { ) }\end{array}$ & $\begin{array}{l}\geq 1 \text { serve } \\
\geq 3 \text { serves }\end{array}$ & $\begin{array}{l}1.5 \\
0.5\end{array}$ & 2 \\
\hline $\begin{array}{l}\text { 4. Include milk, } \\
\text { yoghurts, } \\
\text { cheese and/or } \\
\text { alternatives }\end{array}$ & $\begin{array}{l}\text { Total dairy serves/d } \\
\text { Ratio of skimmed/low } \\
\text { fat (S/LF) intake: whole } \\
\text { milk intake }\end{array}$ & $\begin{array}{l}\geq 2-3 \text { serves } \\
\geq 3-4 \text { serves } \\
1-<2 \text { serves } \\
>4 \text { serves } \\
0-<1 \text { serves } \\
\text { S/LF }>\text { whole milk } \\
\text { S/LF=whole milk } \\
\text { Whole milk }>\text { S/LF }\end{array}$ & $\begin{array}{l}1.5 \\
1.0 \\
1.0 \\
0.5 \\
0 \\
0.5 \\
0.25 \\
0\end{array}$ & 2 \\
\hline
\end{tabular}




\begin{tabular}{|c|c|c|c|c|}
\hline $\begin{array}{l}\text { Dietary guideline/ } \\
\text { component }\end{array}$ & Score & Component subscore & & Total score \\
\hline $\begin{array}{l}\text { 5. Limit saturated } \\
\text { fat and } \\
\text { moderate } \\
\text { total fat intake }\end{array}$ & $\begin{array}{l}\text { Percentage of energy } \\
\text { from saturated fat } \\
\text { Fish serves/week }\end{array}$ & $\begin{array}{l}<10 \% \text { energy } \\
10-12 \% \text { energy } \\
>12 \% \text { energy } \\
\geq 2 \text { serves } \\
1-<2 \text { serves } \\
<1 \text { serve }\end{array}$ & $\begin{array}{l}1 \\
0.5 \\
0 \\
1 \\
0.5 \\
0\end{array}$ & 2 \\
\hline $\begin{array}{l}\text { 6. Choose foods } \\
\text { low in salt }\end{array}$ & $\mathrm{Na}$ intake/d & $\begin{array}{l}\leq 40 \mathrm{mmol}(920 \mathrm{mg}) \\
>40-\leq 100 \mathrm{mmol}(920-2300 \mathrm{mg}) \\
>100 \mathrm{mmol}(2300 \mathrm{mg})\end{array}$ & $\begin{array}{l}2 \\
1 \\
0\end{array}$ & 2 \\
\hline $\begin{array}{l}\text { 7. Limit alcohol } \\
\text { intake if you } \\
\text { choose to } \\
\text { drink }\end{array}$ & $\begin{array}{l}\text { Alcohol intake/d } \\
\text { Women } \\
\text { Men }\end{array}$ & $\begin{array}{l}\geq 0 \mathrm{~g}-<10 \mathrm{~g} \\
\geq 10 \mathrm{~g}-<20 \mathrm{~g} \\
\geq 20 \mathrm{~g} \\
\geq 0 \mathrm{~g}-<20 \mathrm{~g} \\
\geq 20 \mathrm{~g}\end{array}$ & $\begin{array}{l}2 \\
1 \\
0 \\
2 \\
0\end{array}$ & 2 \\
\hline $\begin{array}{l}\text { 8. Consume only } \\
\text { moderate } \\
\text { amounts of } \\
\text { sugars and } \\
\text { foods with } \\
\text { added sugars }\end{array}$ & $\begin{array}{l}\text { Percentage of energy } \\
\text { from sugar }\end{array}$ & $\begin{array}{l}<15 \% \text { total energy } \\
\geq 15-<20 \% \text { total energy } \\
\geq 20 \% \text { energy }\end{array}$ & $\begin{array}{l}2 \\
1 \\
0\end{array}$ & 2 \\
\hline $\begin{array}{l}\text { 9. Extra foods, } \\
\text { not essential } \\
\text { to provide } \\
\text { nutrients and } \\
\text { maybe high in } \\
\text { salt, fat or } \\
\text { sugar }\end{array}$ & $\begin{array}{l}\text { Extra food serves/d } \\
\text { Women } \\
\text { Men }\end{array}$ & $\begin{array}{l}<2 \cdot 5 \text { serves } \\
2 \cdot 5-<4 \text { serves } \\
>4 \text { serves } \\
<3 \text { serves } / d \\
3-<5 \text { serves } \\
\geq 5 \text { serves }\end{array}$ & $\begin{array}{l}2 \\
1 \\
0 \\
2 \\
1 \\
0\end{array}$ & 2 \\
\hline $\begin{array}{l}\text { 10. Prevent weight } \\
\text { gain: be } \\
\text { physically } \\
\text { active and eat } \\
\text { according to } \\
\text { energy needs }\end{array}$ & $\begin{array}{l}\text { Ratio of energy intake } \\
\text { to energy expenditure } \\
\text { Physical activity (METs) }\end{array}$ & $\begin{array}{l}0.76-1.24 \\
<0.76 \text { or }>1.24 \\
\text { Lowest tertile } \\
\text { Middle tertile } \\
\text { Highest tertile }\end{array}$ & $\begin{array}{l}1 \\
0 \\
0 \\
0 \cdot 5 \\
1\end{array}$ & 2 \\
\hline $\begin{array}{l}\text { Drink plenty of } \\
\text { water }\end{array}$ & \multicolumn{3}{|l|}{ Not scored } & \\
\hline Care for food & \multicolumn{3}{|l|}{ Not scored } & \\
\hline Total score & & & & 20 \\
\hline
\end{tabular}

Fig. 1. Scoring system for the Total Diet Score based on the Australian Dietary Guidelines and the Australian Guide to Healthy Eating. * Vegetables: 7 serves, as indicated by weighed food records (FFQ overestimates) (replacing five serves). †Fruit: 3 serves, as indicated by weighed food records (FFQ overestimates) (replacing two serves). S/LF, skimmed/low fat; MET, metabolic equivalents.

weight $(\mathrm{kg})$ divided by height $\left(\mathrm{m}^{2}\right)$, which were measured at baseline examinations using standardised methods. The following two BMI variables were created: 'low BMI' defined as $<20 \mathrm{~kg} / \mathrm{m}^{2}$ and 'high BMI' defined as $\geq 30 \mathrm{~kg} / \mathrm{m}^{2}$. Education was classified as either 'non-qualified', having a high school diploma or less, or 'qualified', having any post-school qualification (including trade certificate, diploma and/or degree).

Blood pressure was measured after sitting for at least $10 \mathrm{~min}$, using standardised methods. Hypertension was defined using the 2003 WHO guidelines, taking as hypertensive grade 2 or above (severe hypertension), which included persons previously diagnosed as hypertensive and currently using anti-hypertensive medications, or those with a systolic blood pressure $\geq 160 \mathrm{mmHg}$ or diastolic blood pressure $\geq 100 \mathrm{mmHg}$ at examination. A history of acute myocardial infarction, stroke or cancer was self-reported by subjects who answered yes to the question 'Has a doctor advised you that you have any of the following conditions?'. Walking disability was assessed by the examiner during the clinic visit in subjects who had walking difficulties or used a cane/crutches/walker or a wheel chair. Leucocyte count was measured from fasting blood samples and determined using the Coulter counter method. Dietary 
supplement users were defined as individuals who consumed supplement(s) for a minimum of $4 \mathrm{~d} /$ week at least 2 months before the study.

\section{Statistical analysis}

All statistical analyses were performed using SAS (version 9.1; SAS Institute). Quintiles of TDS were created from the overall study population and the mean intake of selected foods was calculated for each quintile. Regression models were used to calculate mortality hazard risk (HR) ratios with 95\% CI for each quintile. The first multivariate model was adjusted for age and sex; the second model adjusted for age, sex and lifestyle variables including smoking, BMI, education and diet supplement use. A final multivariate model was adjusted additionally for poor self-reported health, hypertension, diabetes, acute myocardial infarction, stroke, cancer, leucocyte count and walking disability. Quintile 1 (lowest) was used as the reference group and $P$ for trend $<0.05$ was considered significant. The data were also analysed as continuous scores to determine mortality risk for each standard deviation increase in TDS for all multivariate models
(1 SD $=2 \cdot 19)$. Sensitivity analysis was performed by excluding one component at a time from the TDS to determine whether any individual component influenced the total score.

\section{Results}

Baseline characteristics of the subjects are given by quintile of TDS in Table 1. Women, non-smoking subjects and those with post-high school qualifications had trends for increasing TDS. Decreasing trends by TDS quintile $(P$ for trend $<0.05)$ were found for the number of subjects who self-reported fair or poor health.

In this population of older Australians, the baseline TDS ranged from a minimum score of 2.97 to a maximum of $15 \cdot 40$, out of a possible score of 20 (Table 2). Table 2 gives the total mean intakes of the core food groups with greater intakes of fish, fruit and vegetables, cereals, breads and cereal-based products and all milk products in persons with higher TDS ( $P$ for trend $<0.0001$ for all). As an important part of the core food groups, the mean intakes of optimal choice foods were also analysed separately (Table 2). Consistent with the design of the TDS, the number of older

Table 1. Baseline characteristics of the subjects by Total Diet Score quintile ( $n$ 2897)

\begin{tabular}{|c|c|c|c|c|c|}
\hline & Quintile $1(\%)$ & Quintile 2 (\%) & Quintile $3(\%)$ & Quintile $4(\%)$ & Quintile $5(\%)$ \\
\hline$n$ & 579 & 580 & 578 & 583 & 577 \\
\hline \multicolumn{6}{|l|}{ Age (years) } \\
\hline Mean & $65 \cdot 5$ & $65 \cdot 8$ & $65 \cdot 3$ & $64 \cdot 6$ & $65 \cdot 7$ \\
\hline SD & $9 \cdot 9$ & 9.5 & $9 \cdot 7$ & 8.9 & 8.5 \\
\hline \multicolumn{6}{|l|}{$\operatorname{Sex}(n 2897)$} \\
\hline Female & 43.7 & $51 \cdot 0$ & $56 \cdot 1$ & $59 \cdot 0$ & $70 \cdot 0^{\star}$ \\
\hline \multicolumn{6}{|l|}{ Marital status ( $n$ 2893) } \\
\hline Married or de facto & $64 \cdot 7$ & $67 \cdot 0$ & $66 \cdot 9$ & $70 \cdot 8$ & $62 \cdot 2$ \\
\hline Divorced or separated & $10 \cdot 9$ & $10 \cdot 5$ & $11 \cdot 1$ & $9 \cdot 6$ & $13 \cdot 0$ \\
\hline Widowed & $16 \cdot 4$ & $15 \cdot 4$ & $14 \cdot 9$ & $12 \cdot 5$ & $17 \cdot 5$ \\
\hline \multirow{2}{*}{\multicolumn{6}{|c|}{ BMI $\left(\mathrm{kg} / \mathrm{m}^{2}\right)(n$ 2856) }} \\
\hline & & & & & \\
\hline Low $<20 \mathrm{~kg} / \mathrm{m}^{2}$ & $6 \cdot 2$ & 5.5 & $5 \cdot 1$ & $3 \cdot 3$ & $5 \cdot 2$ \\
\hline Moderate $20-<30 \mathrm{~kg} / \mathrm{m}^{2}$ & $77 \cdot 1$ & $77 \cdot 3$ & 74.6 & 79.5 & $79 \cdot 3$ \\
\hline High $\geq 30 \mathrm{~kg} / \mathrm{m}^{2}$ & $16 \cdot 7$ & $17 \cdot 3$ & $20 \cdot 3$ & $17 \cdot 2$ & $15 \cdot 5$ \\
\hline \multicolumn{6}{|l|}{ Smoking status ( $n$ 2777) } \\
\hline Never & $38 \cdot 0$ & $41 \cdot 0$ & $48 \cdot 8$ & $57 \cdot 2$ & $59 \cdot 3$ \\
\hline Past & $38 \cdot 7$ & $41 \cdot 3$ & $35 \cdot 7$ & $34 \cdot 3$ & $34 \cdot 3$ \\
\hline Current & $23 \cdot 3$ & $17 \cdot 7$ & $15 \cdot 6$ & 8.5 & $6 \cdot 4^{\star}$ \\
\hline \multicolumn{6}{|l|}{ Physical activity ( $n$ 2841) } \\
\hline Low & 59.9 & $58 \cdot 1$ & $50 \cdot 7$ & $43 \cdot 2$ & 37.5 \\
\hline Moderate & $27 \cdot 0$ & $22 \cdot 5$ & $26 \cdot 7$ & $29 \cdot 1$ & $31 \cdot 3$ \\
\hline High & $13 \cdot 1$ & 19.4 & $22 \cdot 6$ & $27 \cdot 7$ & $31 \cdot 3^{*}$ \\
\hline \multicolumn{6}{|l|}{ Education ( $n$ 2762) } \\
\hline Tertiary & 54.5 & $60 \cdot 2$ & $59 \cdot 1$ & $62 \cdot 5$ & $61 \cdot 8^{*}$ \\
\hline Diet supplement use ( $n$ 2897) & $30 \cdot 1$ & $35 \cdot 0$ & $34 \cdot 3$ & $36 \cdot 7$ & $48 \cdot 3^{*}$ \\
\hline \multicolumn{6}{|l|}{ Self-reported health ( $n$ 2858) } \\
\hline Excellent/good & $70 \cdot 9$ & 74.3 & $77 \cdot 2$ & $82 \cdot 0$ & 79.9 \\
\hline Fair/poor & $29 \cdot 1$ & $25 \cdot 8$ & $22 \cdot 8$ & $18 \cdot 0$ & $20 \cdot 1^{*}$ \\
\hline Walking disability ( $n$ 2888) & $7 \cdot 3$ & $3 \cdot 1$ & $5 \cdot 7$ & $4 \cdot 0$ & 4.4 \\
\hline Hypertension (n 2888) & $45 \cdot 9$ & $46 \cdot 0$ & $46 \cdot 3$ & $42 \cdot 1$ & $46 \cdot 7$ \\
\hline Diabetes ( $n$ 2897) & $5 \cdot 2$ & $6 \cdot 9$ & 5.4 & 8.9 & $10 \cdot 1^{*}$ \\
\hline AMI $(n 2893)$ & $6 \cdot 2$ & 7.9 & 8.7 & $8 \cdot 6$ & $10 \cdot 8^{*}$ \\
\hline Stroke (n 2894) & $6 \cdot 0$ & $5 \cdot 0$ & 4.5 & $4 \cdot 0$ & 4.0 \\
\hline Cancer (n 2894) & 8.5 & $7 \cdot 9$ & $9 \cdot 2$ & $8 \cdot 3$ & 8.5 \\
\hline
\end{tabular}

AMI, acute myocardial infarction.

${ }^{*} P$ for trend $<0.05$. 
Australians reporting consumption of optimal choice foods increased through the quintiles for all major food groups. For example, mean wholemeal/whole-grain cereal intake increased by $137 \%$ through quintiles $1-5$. Total dairy intake increased by $31 \%$ between quintile 1 and quintile 5 , yet intake of low- or reduced-fat milk increased by $224 \%$ from the lowest to the highest quintile of TDS.

During the 15-year follow-up, 1047 (36.2\%) subjects died. Participants with higher TDS had a lower risk of all-cause mortality. Subjects in quintile 5 had a significant $21 \%$ decreased risk of all-cause mortality compared with the reference group (quintile 1) (multivariate-adjusted HR 0.79 , 95\% CI $0.63,0.98, P$ for trend $=0.04)$ and a $23 \%$ decreased risk of cardiovascular mortality (adjusted HR $0 \cdot 77$, 95\% CI $0 \cdot 57,1 \cdot 05, P$ for trend $=0 \cdot 1$ ) (Table 3 ). No association between diet quality and cancer mortality was found in any of the models (Table 3). Sex was assessed as a potential effect modifier but no statistically significant interaction was found (Table 3), and therefore we decided not to stratify by sex. In addition, we re-ran the analysis after excluding subjects ( $n$ 98) who died within the first 2 years of follow-up and found similar results for both all-cause mortality (adjusted HR $0.83,95 \%$ CI $0.66,1.04)$ and CVD mortality (adjusted HR $0.76,0.57,1.01)$.

We also examined TDS as a continuous variable and observed an $8 \%(P=0.02)$ decrease in multivariate-adjusted all-cause mortality per standard deviation increase in TDS $(1 \mathrm{SD}=2.19$ units; HR 0.92, 95\% CI 0.86, 0.99). A similar decrease in cardiovascular mortality was observed for each standard deviation increase in TDS (HR 0.91, 95\% CI 0.82, 1.00) but not for cancer mortality.

We performed sensitivity analysis to determine whether the association between TDS and mortality was influenced by any specific individual TDS component. Each component was removed, one at a time, from the total score and the analysis was then conducted again. This analysis demonstrated that the present results were not sensitive to the removal of any single component and the trend was similar for all models (see Supplementary material 2, available online).

\section{Discussion}

The present findings show that, overall, older Australians who more closely followed the DGAA had a significantly lower all-cause mortality risk over the next 15 years. Further, participants with higher levels of diet quality included significantly greater quantities of a range of recommended optimal choice foods in their diets, suggesting that following the current Australian dietary guidelines may reduce the likelihood of all-cause mortality.

The goals of different diet quality indices may influence the relationship between diet quality and the risk of chronic disease and/or mortality ${ }^{(12)}$. Predicting health outcomes often depends on the purpose of the index, for example both the Diet Quality Index and Healthy Eating Index (HEI) were adapted to improve chronic disease risk prediction and the alternative HEI was found to have greater capacity to

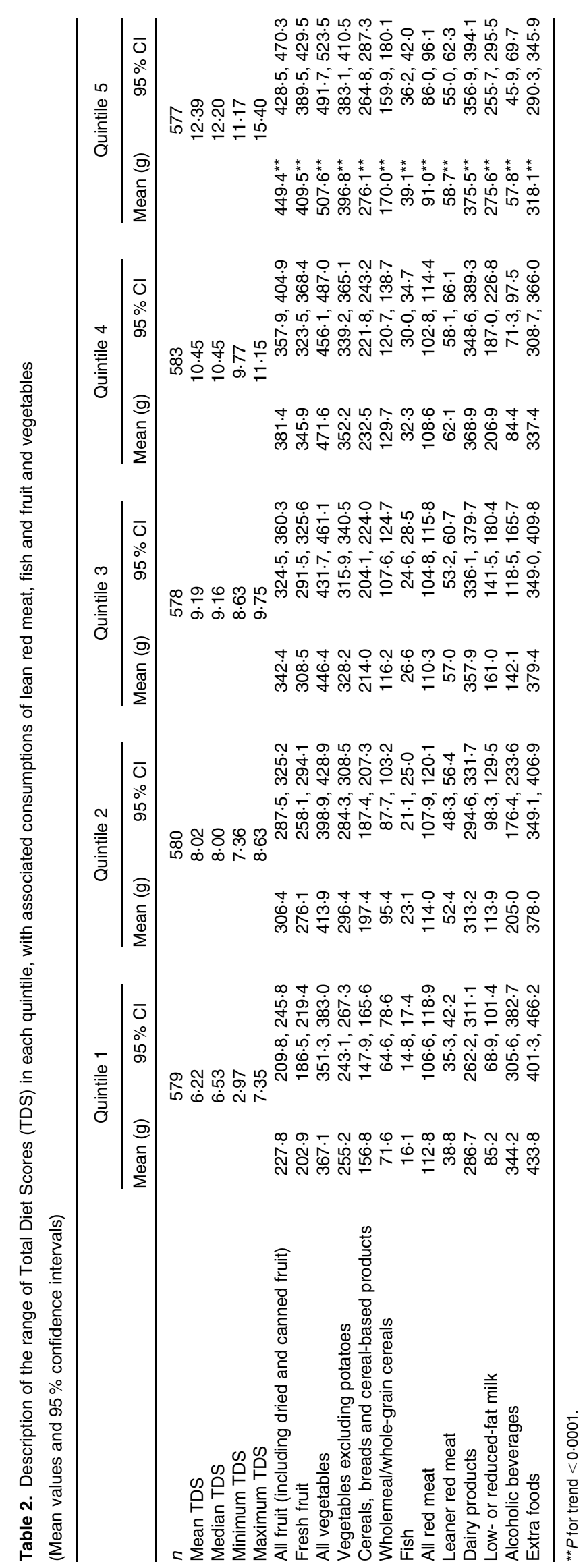


Table 3. Total Diet Score (TDS) and risk of total and cause-specific mortality by quintile of TDS and as a continuous variable (Hazard risk ratios (HRR) and $95 \%$ confidence intervals)

\begin{tabular}{|c|c|c|c|c|c|c|c|c|c|c|}
\hline \multirow[b]{2}{*}{ TDS quintile } & \multirow[b]{2}{*}{ Subjects $(n)$} & \multicolumn{2}{|c|}{ Deaths } & \multicolumn{3}{|c|}{ HRR by TDS quintile* } & \multirow[b]{2}{*}{ Sex interaction } & \multicolumn{3}{|c|}{$\begin{array}{l}\text { HRR by standard deviation } \\
\text { of TDS* }\end{array}$} \\
\hline & & $n$ & $\%$ & HRR & $95 \% \mathrm{Cl}$ & $P$ for trend & & HRR & $95 \% \mathrm{Cl}$ & $P$ for trend \\
\hline All-cause mortality & & & & & & & & 0.92 & $0.86,0.99$ & 0.02 \\
\hline Quintile 1 & 477 & 194 & 41 & $1 \cdot 0$ & Ref & 0.04 & $P=0.62$ & & & \\
\hline Quintile 2 & 484 & 180 & 37 & 0.92 & $0 \cdot 75,1 \cdot 13$ & & & & & \\
\hline Quintile 3 & 503 & 179 & 36 & 0.95 & $0.78,1.17$ & & & & & \\
\hline Quintile 4 & 509 & 162 & 32 & 0.90 & $0.73,1.11$ & & & & & \\
\hline Quintile 5 & 517 & 153 & 30 & 0.79 & $0.63,0.98$ & & & & & \\
\hline Cardiovascular mortality & & & & & & & & 0.91 & $0.82,1.00$ & 0.06 \\
\hline Quintile 1 & 477 & 95 & 20 & 1.0 & Ref & 0.1 & $P=0.74$ & & & \\
\hline Quintile 2 & 484 & 94 & 19 & 0.92 & $0.69,1.23$ & & & & & \\
\hline Quintile 3 & 502 & 100 & 20 & 1.05 & $0.79,1.40$ & & & & & \\
\hline Quintile 4 & 509 & 85 & 17 & 0.92 & $0.68,1.25$ & & & & & \\
\hline Quintile 5 & 517 & 79 & 15 & 0.77 & $0.57,1.05$ & & & & & \\
\hline Cancer mortality & & & & & & & & 0.98 & $0 \cdot 87,1 \cdot 11$ & 0.8 \\
\hline Quintile 1 & 477 & 57 & 12 & 1.0 & Ref & 0.8 & $P=0.94$ & & & \\
\hline Quintile 2 & 484 & 64 & 13 & $1 \cdot 14$ & $0.80,1.63$ & & & & & \\
\hline Quintile 3 & 503 & 61 & 12 & 1.09 & $0.76,1.58$ & & & & & \\
\hline Quintile 4 & 509 & 56 & 11 & 1.01 & $0.69,1.47$ & & & & & \\
\hline Quintile 5 & 517 & 54 & 10 & 1.01 & $0.69,1.49$ & & & & & \\
\hline
\end{tabular}

Ref, reference.

*Adjusted for age, smoking BMI (low, high), education, dietary supplement use, self-reported poor health, hypertension, diabetes, acute myocardial infarction, stroke, cancer, leucocyte count and walking disability.

predict chronic disease risk ${ }^{(28)}$. The aim of the TDS was to examine overall diet and how closely participants adhered to the DGAA and the AGHE as well as to determine whether following the dietary guidelines reduced the risk of mortality. Another diet quality index, the Recommended Food Score, has been found to predict chronic disease risk better than more complex indices. However, the Recommended Food Score scoring system only scores intakes of recommended foods in the diet, in particular fruit and vegetable intake, and does not consider energy-dense nutrient-poor foods, such as extra foods ${ }^{(2)}$.

An inverse association between diet quality and the risk of all-cause mortality and cause-specific mortality has been reported in a number of studies. These findings were based on reduced mortality risk and adherence to a Mediterranean diet pattern ${ }^{(29)}$ and the WHO's guidelines for preventing chronic disease ${ }^{(30)}$. However, results from indices that are based more closely on published dietary guidelines do not show a consistent inverse relationship between diet quality and all-cause mortality, CVD or cancer mortality ${ }^{(31,32)}$. The evidence for a relationship between diet quality and cancer mortality is inconsistent in adults. The present nonsignificant findings for cancer mortality after multivariate adjustment are similar to other studies that have used different diet quality indices ${ }^{(31-33)}$. There are many different types of cancer and the effect of dietary factors varies between different cancer sites. However, we only investigated total cancer mortality and had insufficient power to explore sitespecific cancer types.

The inconsistent findings could be explained by the low level of compliance to dietary guidelines and the reduction in the risk of mortality or the development of chronic disease may be improved if overall diets were improved. The results from the present study suggest poor compliance with dietary guidelines with the maximum score reaching approximately $75 \%$ compliance to dietary guidelines, which is consistent with other findings in the Australian population ${ }^{(34,35)}$. However, even at this level, we found a significant decrease in the risk of all-cause mortality in those who had greater compliance. The present significant findings of higher diet quality in those who had an existing diagnosis of diabetes or acute myocardial infarction suggest that older adults may be willing to change their diet due to health reasons but as the baseline data in the present study were cross-sectional, it is not possible to explain these results fully.

The TDS differs from other indices in a number of ways. The dietary guidelines were designed to be applied to the total diet with no individual guidelines being considered in isolation; therefore, we gave each component equal weighting. Under the heading of enjoying a wide variety of nutritious foods, we considered four core groups, keeping vegetables, legumes and fruits as one component as described in the DGAA. We included a score for the non-dietary component prevention of weight gain measured by energy balance ratio and physical activity levels that has been excluded from previous diet quality indices ${ }^{(18,34)}$. The importance of regular physical activity is emphasised by its inclusion in the DGAA since 1992 as part of maintaining a healthy body weight ${ }^{(22)}$. 'Extra' foods were considered as an individual component because they capture many energy-dense nutrient-poor foods that are not included in the core food groups and may only partly contribute to nutrient intake. These are highlighted in the AGHE which provides materials for the general public to use to help manage their diet. It has been reported that 'extra' foods contributed $36 \%$ of energy from sugars in Australian adults, considerably higher than 
the recommended levels and $99 \cdot 1 \%$ consumed at least one 'extra' food ${ }^{(24)}$.

To our knowledge, this is the first Australian study to examine longitudinal data assessing the relationship between diet quality and mortality using a tool based on the DGAA and AGHE. Cross-sectional studies in Australia to date have reported generally higher nutrient intakes with higher diet quality scores ${ }^{(34,36)}$. There were no known validated Australian diet quality indices at the time the TDS was developed; therefore, an index assessing the 2005 American Dietary Guidelines was reviewed that distinguished between food intake relating to energy and optimal choice recommendations to make improvements to the $\operatorname{TDS}^{(18)}$. The significant trend for higher consumption of fruits and vegetables, fish, whole-grain breads and cereals across the TDS quintiles is similar to the findings from studies in the USA, Europe and Australia ${ }^{(16,37-40)}$. However, the variety of scoring methods for diet quality such as the Recommended Food Score and Mediterranean Diet Score, length of mortality follow-up and differing covariate adjustments limits direct comparison of the present findings with other studies. With regard to potential confounders, we adjusted for known modifiable health behaviours in the second model but not for alcohol and physical activity levels, as these were included as components of the TDS. For the final multivariate model, we adjusted for a range of health conditions including chronic diseases and walking disability which are known to be related to diet ${ }^{(41)}$.

The present study has a number of limitations. Using FFQ for self-reported dietary intake can underestimate energy intake $^{(42)}$ or overestimate fruit, vegetable and dairy intakes $^{(43,44)}$. To allow for this overestimation, we increased the cut point for fruit and vegetable intake per $d$ to three serves and seven serves, respectively. However, the present results provide a good indicator of the proportion of optimal foods consumed between those in the lowest to highest quintile of TDS. For example, total red meat intake reduced from quintile 1 to quintile 5, while choosing leaner red meat cuts increased across the quintiles in the opposite direction. The reduction in red meat intake could be explained by higher fish intake with intakes increasing by $143 \%$ from the lowest to the highest quintile of TDS. In addition, the FFQ only measures diet at one time point and not over a lifetime. However, older adults may have established eating patterns that remain constant over time ${ }^{(42)}$.

A further limitation is the assumption that the dietary guidelines used to define diet quality indices are based on the best available scientific knowledge, though this may not necessarily be the case as it is difficult to keep dietary guidelines up to date ${ }^{(45)}$. The DGAA were developed to provide guidelines for diet targeting overall health and well-being, but they are not disease specific and may provide protective benefits for some diseases and not others ${ }^{(46)}$. Many subjects had at least one chronic disease at baseline, which was adjusted for in model 2 of the present analysis. The data were reanalysed, excluding participants who died within 2 years of baseline and the results were similar throughout. However, there is the possibility that residual confounding may have influenced the associations between mortality and dietary intakes. Although we accounted for known confounders, mortality causation is multifactorial and there may be other confounding factors that need to be considered. The strengths of the present study include its high response rate in a population-based sample as well as detailed data collection enabling us to assess a wide range of potential confounders. The present study population is representative of the Australian population in the same age group, except for a slightly higher SES shown by a higher proportion who owned their home, a higher proportion with qualifications after leaving school and a lower proportion of manual workers $^{(47)}$.

In conclusion, these data provide useful information about the relationship between adhering to dietary guidelines and mortality risk in a representative older Australian population. As assessment of diet quality was based on adherence to the DGAA, the TDS could be applied to longitudinal data assessing the effects of diet quality and morbidity or mortality risk in other Australian adult populations.

\section{Acknowledgements}

This study was supported by the Australian National Health and Medical Research Council, Canberra Australia (grant no. 974159, 211069) and Meat and Livestock Australia (MLA). The authors' responsibilities were as follows: P. M., V. F., M. A.-F. and A. B. contributed to the study concept and design; P. M., V. F., E. R. collected the data; J. R. and E. R. conducted the data analysis; J. R. and V. F. drafted the manuscript; J. R., V. F., E. R., B. G., M. A.-F., A. B. and P. M. critically reviewed the final draft of the manuscript. The authors declare that there are no conflicts of interest.

Supplementary material is available online at http:// journals.cambridge.org/bjn

\section{References}

1. Osler M \& Schroll M (1997) Diet and mortality in a cohort of elderly people in a North European community. Int J Epidemiol 26, 155-159.

2. Kant AK, Schatzkin A, Graubard BI, et al. (2000) A prospective study of diet quality and mortality in women. J Am Med Assoc 283, 2109-2115.

3. Michels KB \& Wolk A (2002) A prospective study of variety of healthy foods and mortality in women. Int $J$ Epidemiol 31, 847-854.

4. Knoops K, Groot de L, Fidanza F, et al. (2006) Comparison of three different dietary scores in relation to 10-year mortality in elderly European subjects: the HALE project. Eur J Clin Nutr 60, 746-755.

5. Harriss LR, English DR, Powles J, et al. (2007) Dietary patterns and cardiovascular mortality in the Melbourne Collaborative Cohort Study. Am J Clin Nutr 86, 221-229.

6. Kaluza J, Hakansson N, Brzozowska A, et al. (2009) Diet quality and mortality: a population-based prospective study of men. Eur J Clin Nutr 63, 451-457.

7. Heidemann C, Schulze MB, Franco OH, et al. (2008) Dietary patterns and risk of mortality from cardiovascular disease, 
cancer, and all cases in a prospective cohort of women. Circulation 118, 230-237.

8. Brunner EJ, Mosdol A, Witte DR, et al. (2008) Dietary patterns and 15-y risks of major coronary events, diabetes, and mortality. Am J Clin Nutr 87, 1414-1421.

9. Bamia C, Trichopoulos D, Ferrari P, et al. (2007) Dietary patterns and survival of older Europeans: The EPIC-Elderly Study (European Prospective Investigation into Cancer and Nutrition). Public Health Nutr 10, 590-598.

10. Waijers P, Ocke M, van Rossum CT, et al. (2006) Dietary patterns and survival in older Dutch women. Am J Clin Nutr 83, $1170-1176$.

11. Newby PK \& Tucker KL (2004) Empirically derived eating patterns using factor or cluster analysis: a review. Nutr Rev 62, 177-203.

12. Waijers P, Feskens E \& Ocke M (2007) A critical review of predefined diet quality scores. Br J Nutr 97, 219-231.

13. Haines PS, Siega-Riz AM \& Popkin BM (1999) The Diet Quality Index revised: a measurement instrument for populations. J Am Diet Assoc 99, 697-704.

14. Kennedy E, Ohls J, Carlson S, et al. (1995) The Healthy Eating Index: design and applications. J Am Diet Assoc 95, $1103-1108$

15. Harnack L, Nicodemus K, Jacobs DR Jr, et al. (2002) An evaluation of the dietary guidelines for Americans in relation to cancer occurrence. Am J Clin Nutr 76, 889-896.

16. McNaughton SA, Dunstan DW, Ball K, et al. (2009) Dietary quality is associated with diabetes and cardio-metabolic risk factors. J Nutr 139, 734-742.

17. Australian Institute of Health and Welfare (2007) Australian Diet Quality Index Project. Canberra: Australian Institute of Health and Welfare. AIHW cat no. PHE 85.

18. Fogli-Cawley J, Dwyer J, Saltzman E, et al. (2006) The 2005 dietary guidelines for Americans adherence index: development and application. J Nutr 136, 2908-2915.

19. Smith W, Mitchell P, Reay EE, et al. (1998) Validity and reproducibility of a self-administered food frequency questionnaire in older people. Aust NZ J Public Health 22, 456-463.

20. Mitchell P, Smith W, Webb K, et al. (1995) Prevalence of age-related maculopathy in Australia: the Blue Mountains Eye Study. Ophthalmology 102, 1450-1460.

21. Flood VM, Smith WT, Webb K, et al. (2004) Issues in assessing the validity of nutrient data obtained from a food-frequency questionnaire: folate and vitamin $\mathrm{B}_{12}$ examples. Public Health Nutr 7, 751-756.

22. National Health Medical Research Council (2003) Dietary Guidelines for Australian Adults. Canberra: National Health and Medical Research Council.

23. Smith A, Kellett E \& Schmerlaib Y (1998) Guide to Healthy Eating. Canberra: Commonwealth Department of Health \& Family Service.

24. Rangan AM, Schindeler S, Hector DJ, et al. (2009) Consumption of 'extra' foods by Australian adults: types, quantities and contribution to energy and nutrient intakes. Eur J Clin Nutr 63, 865-871.

25. Black AE (2000) The sensitivity and specificity of the Goldberg cut-off for EI:BMR for identifying diet reports of poor validity. Eur J Clin Nutr 54, 395-404.

26. Risk Factor Prevalence Study Management Committee (1990) Risk Factor Prevalence Study: Survey No. 3 1989. Canberra: National Heart Foundation of Australia and Australian Institute of Health.

27. Brown WJ \& Bauman AE (2000) Comparison of estimates of population levels of physical activity using two measures. Aust N Z J Public Health 24, 520-525.
28. Wirt A \& Collins CE (2009) Diet quality - what is it and does it matter? Public Health Nutr 12, 2473-2492.

29. Trichopoulos A, Costacou T, Bamia C, et al. (2003) Adherence to a Mediterranean diet and survival in a Greek population. $N$ Engl J Med 348, 2599-2608.

30. Huijbregts P, Feskens E, Rasanen L, et al. (1997) Dietary pattern and 20 year mortality in elderly men in Finland, Italy, and the Netherlands: longitudinal cohort study. BMJ 315, 13-17.

31. McCullough M, Feskanich D, Rimm EB, et al. (2000) Adherence to the dietary guidelines for Americans and risk of major chronic disease in men. Am J Clin Nutr 72, 1223-1231.

32. McCullough M, Feskanich D, Stampfer M, et al. (2000) Adherence to the dietary guidelines for Americans and risk of major chronic disease in women. Am J Clin Nutr 72, 1214-1222.

33. Seymour J, Calle E, Flagg E, et al. (2003) Diet Quality Index as a predictor of short-term mortality in the American Cancer Society Cancer Prevention Study II Nutrition Cohort. $\mathrm{Am} \mathrm{J}$ Epidemiol 127, 980-988.

34. McNaughton SA, Ball K, Crawford D, et al. (2008) An index of diet and eating patterns is a valid measure of diet quality in an Australian population. $J$ Nutr 138, 86-93.

35. Arabshahi S, Lahmann PH, Williams GM, et al. (2011) Longitudinal change in diet quality in Australian adults varies by demographic, socio-economic, and lifestyle characteristics. J Nutr 141, 1871-1879.

36. Collins CE, Young AF \& Hodge AM (2008) Diet quality is associated with higher nutrient intake and self-rated health in mid-aged women. J Am Coll Nutr 27, 146-157.

37. Hann CS, Rock CL, King I, et al. (2001) Validation of the Healthy Eating Index with use of plasma biomarkers in a clinical sample of women. Am J Clin Nutr 74, 479-486.

38. Toft U, Kristoffersen LH, Lau C, et al. (2007) The Dietary Quality Score: validation and association with cardiovascular risk factors: the Inter99 study. Eur J Clin Nutr 61, 270-278.

39. Drewnowski A, Fiddler E, Dauchet L, et al. (2009) Diet quality measures and cardiovascular risk factors in France: applying the healthy eating index to the SU.VI.MAX Study. $J$ Am Coll Nutr 28, 22-29.

40. Bondia-Pons I, Mayneris-Perxachs J, Serra-Majem L, et al. (2010) Diet quality of a population sample from coastal north-east Spain evaluated by a Mediterranean adaptation of the diet quality index (DQI). Public Health Nutr 13 $12-24$.

41. Fung TF, McCullough M, Van Dam RM, et al. (2007) A prospective study of overall diet quality and risk of type 2 diabetes in women. Diabetes Care 30, 1753-1757.

42. Cade J, Burley V, Warm D, et al. (2004) Food-frequency questionnaires: a review of their design, validation and utilisation. Nutr Res Rev 17, 5-22.

43. Bingham S, Welch A, McTaggart A, et al. (2001) Nutritional methods in the European Prospective Investigation of Cancer in Norfolk. Public Health Nutr 4, 847-858.

44. Ibiebele T, Parekh S, Mallitt K, et al. (2009) Reproducibility of food and nutrient intake estimates using a semi-quantitative FFQ in Australian adults. Public Health Nutr 12, 2359-2365.

45. Hu FB (2002) Dietary pattern analysis: a new direction in nutritional epidemiology. Curr Opin Lipidol 13, 3-9.

46. Michels KB \& Schulze MB (2005) Can dietary patterns help us detect diet-disease associations? Nutr Res Rev $\mathbf{1 8}$ 241-248.

47. Webb KL \& Schofield WN (1999) Prevalence and sociodemographic predictors of dietary goal attainment in an older population. Aust N Z J Public Health 23, 578-584. 